\title{
Mixtapes and turntablism: DJs' perspectives on musical shape
}

\author{
ALINKA E. GREASLEY[1] \\ University of Leeds \\ HELEN M. PRIOR[2] \\ King's College London
}

\begin{abstract}
The notion of musical shape is widely used by performing musicians, but most studies have focused on classical performing contexts. This paper extends this research to DJs performing on turntables, chosen in light of existing evidence from a questionnaire study suggesting that shape may be a useful concept for some DJs. This paper presents an interview study investigating the use and understanding of musical shaping by three professional DJs with varied backgrounds. Interpretative Phenomenological Analysis was used to analyse the data. Findings suggest that DJs do use the notion of shape implicitly when planning and executing their sets, and that playing sets without any shaping involves playing the music badly. DJs reported using the idea of shaping to modify a track while it was playing; to help control the transition between tracks; and in relation to the overall trajectory of a set. There was evidence that participants understood musical shaping multi-modally, through gesture and visual representation as well as sound; and results show ways in which DJs draw on heuristics to signify complex combinations of technical devices that create a particular musical shape or sound. The findings are considered in relation to existing work on performers' use of musical shape as well as work on the practice of DJs.
\end{abstract}

Submitted 2013 January 15; accepted 2013 July 23.

KEYWORDS: musical shaping, DJs, mixtapes, turntablism, scratching

\section{INTRODUCTION}

THE notion of musical shape is widely used by performing musicians, but has only recently become more common as a focus of study. Most of the current studies of musical shape or shaping have focussed on classical performing contexts. This paper begins the process of widening the scope of this research to include a specific 'popular' performing context, namely DJs performing on turntables. The nature and potential implications of the specific practices of DJs on their ideas of musical shaping will be considered later; first, existing studies of classical musicians' notions of shaping will be examined.

Performing musicians have been found to use the terms 'shape' or 'shaping' spontaneously in relation to music in performance contexts such as masterclasses; it is also commonly used in writings about music by performers, critics, and musicologists (Daynes, 2010). The term appears to be used with a range of meanings: as a synonym for 'form' or 'structure'; as a term closely related to musical expression; and as an idea related to human movement and gesture.

A more systematic overview of performers' ideas concerning musical shaping is provided by Prior (2012c). This questionnaire study received responses from over 200 performing musicians, many of whom reported that they were of professional standard. They played a wide variety of musical genres, but nearly 60 per cent of the sample seemed to perform music from within the classical genre exclusively. In contrast, only 10 per cent of respondents played non-classical music exclusively. Many more participants played music from both broad genres. The predominance of classical music may reflect the recruitment strategy, which used a 'snowballing' technique whereby contacts at conservatoires and universities were asked to complete the questionnaire and to pass the details on to interested friends and colleagues. One participant 
was a DJ and her responses to the questionnaire will be discussed in the following section; a more general overview of the findings will be provided here.

When asked whether they ever thought about shape when thinking about how to perform music or when talking with others about how to perform music, the vast majority of participants reported doing so, and these participants were able to give detailed descriptions of their experiences. Because participants were asked to provide a date for the experiences they described, it became evident that experiences of using musical shape could be very memorable, or very frequent: some participants described experiences from as many as 40 years ago, whereas others described experiences from the same day or their last rehearsal. The experiences described by participants seemed to take place in private practice, performance, teaching and rehearsal situations. Like the documentary evidence described above, this suggests that the idea of musical shape or shaping is in common use among performing musicians.

The descriptions also revealed that some participants seemed to view musical shape as synonymous with musical structure, and discussed the shape of a whole piece of music or gig set. Other participants discussed specific expressive ideas, such as changes in dynamics, as shape-related ideas. Some participants combined these two themes and described shaping music as realizing the musical structure in an expressive way. Participants also discussed using the idea of shape as an underlying narrative involving climactic moments, direction, and energy, to help them express the music.

Various short answer questions were used in the questionnaire to try to gain an understanding of which music-related ideas were most strongly and commonly related to musical shaping. Certain musical features, such as phrasing, melodic features, and the piece of music as a whole, were seen as being more related to musical shape than others, such as a specific rhythm or a single note. Musical shape was also related to slightly more abstract concepts such as musical gesture, emotion, tension or intensity in the music. Some participants reported visualizing musical shape; for others, it was a more abstract phenomenon, or a metaphor. Overall, then, shape appeared to be complex and multi-faceted, but very useful to musicians.

This questionnaire study prompted a more in-depth study of the use of musical shaping. Prior (2012b) interviewed five professional violinists and five professional harpsichordists. She asked her participants to demonstrate and discuss their normal approaches to a short unfamiliar piece of music; their approaches when focusing on shaping this unfamiliar music; in some cases, their approaches when trying not to shape the music; and their approaches to pieces of music they knew well or had been working on. Using a range of analytical approaches (Prior, 2012a), including Interpretative Phenomenological Analysis (IPA), the analysis of metaphor and gesture, and musicological analysis using Sonic Visualiser, Prior's results showed a range of novel findings. First, participants discussed a range of technical approaches to musical shaping, which varied somewhat according to the instrument played by the performer. Some violinists, for example, discussed shaping an individual note using variations in bow pressure and speed as well as vibrato; whereas harpsichordists were concerned with their touch on the instrument or the spread they used on an individual chord within the context of a phrase. Second, although these technical approaches could be the participants' main focus of attention, many participants appeared to 'skip over' these detailed decision-making processes, using more or less conventionalized metaphorical ideas, like shape or shaping, heuristically to help them create a musically expressive performance (Leech-Wilkinson \& Prior, forthcoming). Third, some of these metaphorical ideas concerning the music and the appropriate musical shaping seemed to be expressed through gesture, exposing participants' multi-modal understanding of musical shaping. In addition to well-established links between pitch and the vertical axis, and time and the horizontal axis, participants seemed to use more fluid gestures such as arches and waves to accompany more metaphorical ideas such as musical shaping. Finally, one participant in particular appeared to have a particularly interesting and close relationship between his musical identity (whether as an individual or as part of his orchestral group) and his musical shaping. He described the ways in which his own background and musical knowledge would feed into his musical shaping. For example, his knowledge of the harmony implied by a particular melody and the emotions he felt that harmony entailed influenced the emphasis he placed on each note and the means by which he created that emphasis. He also described the ways in which he would mould his individual musical shaping to fit that of a particular ensemble, and in turn, the ways in which the technical approaches to that shaping such as fingering or bow pressure would contribute to an ensemble's unique sound (Prior, forthcoming). A conceptual model of musical shaping is currently being developed from these findings with the aim of understanding the ways in which musical shaping operated in relation to a range of musical parameters and temporal scales. 


\section{DJs and musical shaping}

A DJ's act of performance has both similarities with and differences from that of a classical performer. A classical performer traditionally begins the performance preparation process by studying a score, though findings by Ginsborg and Prior (2011) suggest that many younger musicians use recordings as a starting point for learning a new piece. Whichever approach is adopted, the performance materials are specified by someone else, whether that person is a composer or another performer. Many of a DJ's materials are specified by others in as much as they are produced by others (unless the DJ is also a producer working with his or her own materials), but there is far greater freedom of choice in the performance itself as the DJ can decide which, and in what order to play music, and the audience is largely unaware of the selections they are going to make. DJs take a recording that is, in itself, a finished product, and transform it into a new performance. Thus whilst classical performing musicians and DJs are often realizing another musician's conception of a piece of music, this may vary from an exact reproduction of that piece to a radically different performance that may even be considered to be a new piece.

The cultural worlds of classical performers and DJs are very different, as are the ways each type of musician is trained. While a classical performer will usually receive performance training from teachers when they are younger, at school and then at a conservatoire or a university, it is more common for a DJ to learn his or her performance skills informally.[3]

These similarities and differences between classical musicians and DJs inspired the current research, which is designed to assess the extent to which DJs use notions of musical shaping in their performances. The questionnaire study mentioned above (Prior, 2012c) received a single response from a practising DJ, whose responses to the more open-ended questions provided considerable food for thought. This DJ was female, aged between 25 and 34 years, and was born and lives in the UK. She completed the questionnaire on the 30 March 2010. She studied music at two UK Universities as an undergraduate and a postgraduate respectively. She described her main instrument as 'turntables (DJing)' but also reported playing the piano and violin. She had been playing the turntables for less than ten years, and indicated her musical status as being within the category of 'An amateur, intermediate-level performer (none, or a very low proportion of your income comes from performing activities; you are a capable player, but not of professional standards)'. She reported playing music that was within the categories of 'Unaccompanied solo music' and of 'Popular/non-classical music, Dance/electronic (house, techno, electronica etc.)', but also had interests in record production and musicology. Her responses to questions concerning her experience of music and shape are shown in Table 1.

She described a solo performance (making a mixtape) and a 'back-to-back' DJ set (in a nightclub) and both experiences had occurred in the four months prior to her completing the questionnaire. It is interesting that both episodes involved planning a performance and the choice of tracks involved, rather than the act of performance itself. This might be likened to a classical performer choosing a programme for a concert. Interestingly, this participant related the overall shaping of a set (on both the occasions described) to the energy level of the tracks played. There is a desire to consider the overall contour of a mix and a desire to maintain interest for the listener or audience (in the case of the nightclub performance). This too is a useful concept for classical musicians, who in the interview study described above (Prior, 2012b) often discussed the overall contour of a musical work with several movements, and gestured to indicate the energy levels implied within those movements. The DJ participant also discusses the manner in which she could make a transition between tracks as part of the musical shaping, an idea that emphasizes her role as a performer in creating a desirable set. Although this participant's original emphasis was on the planning of sets, this suggests that musical shape is also considered during the act of performance. Like the classical performers in the questionnaire study and interview study, this DJ uses a range of metaphors to describe the musical shape. When asked later about words with a similar meaning to 'shape' in a musical context, she suggested contour, mood, energy level and pattern. 
Table 1. Questionnaire data concerning a DJ's experiences of music and shape

\begin{tabular}{|c|c|c|}
\hline & $\begin{array}{l}\text { Do you ever think about shape when THINKING about how to } \\
\text { perform music? }\end{array}$ & $\begin{array}{l}\text { Do you ever think about shape when } \\
\text { TALKING with others about how to } \\
\text { perform music? }\end{array}$ \\
\hline Response & Yes & Yes \\
\hline \begin{tabular}{|l|} 
When this \\
occurred (i.e. \\
date)
\end{tabular} & December 2009 & March 2010 \\
\hline $\begin{array}{l}\text { The piece of } \\
\text { music }\end{array}$ & A DJ mix I was preparing & Various dance tracks \\
\hline The situation & $\begin{array}{l}\text { I was planning which tracks should go in a mix (approx 50-60 } \\
\text { minutes long) and in what order. }\end{array}$ & $\begin{array}{l}\text { When preparing to DJ in a bar with a } \\
\text { partner - 'back to back' DJing } \\
\text { (alternating } 2 \text { records each) }\end{array}$ \\
\hline \begin{tabular}{|l} 
How shape \\
was used \\
(please give as \\
much detail as \\
possible)
\end{tabular} & $\begin{array}{l}\text { I conceive of certain tracks as being 'higher' than others. This has } \\
\text { to do principally with their mood and energy level. More elevated, } \\
\text { s'peaky' tracks are higher, while more relaxed tracks are 'lower'; } \\
\text { certain tracks - normally called 'tracky' - are quite 'flat' - they keep } \\
\text { the mood and energy level constant. So when thinking about how } \\
\text { to put together a mix, you have a sense of overall contour. You } \\
\text { take care to create a meaningful trajectory both on a large scale } \\
\text { and a smaller scale. For example, on a small scale, you might } \\
\text { alternate high and low tracks to create contrast and a sense of } \\
\text { development (banging in 'peaky' tracks one after another quickly } \\
\text { loses its impact unless carefully done). On a large scale (over a } \\
\text { whole mix) you might combine tracks in such a way as to produce } \\
\text { an arch shape, meaning a mix that gets more and more peaky } \\
\text { towards the middle then tapers off towards the end (this would be } \\
\text { a classic and very common contour). Or you can start off 'flat', } \\
\text { keeping the mood rather level then gradually introduce peaky } \\
\text { elements by stealth, as it were. There are many different possible } \\
\text { strategies, but they all involve thinking about shape. Also, the } \\
\text { manner in which you mix one track into the next also has shape: } \\
\text { you can mix in a 'choppy' way (quickly, making sudden } \\
\text { movements of the faders on four/eight/sixteen bar downbeats), or } \\
\text { you can do a 'smoother fade', which is more gradual and linear. } \\
\text { These produce very different effects: the choppy mixing style is } \\
\text { more exciting as it foregrounds the introduction of the new } \\
\text { elements, but the smooth style is more hypnotic as it emphasises } \\
\text { their continuities. }\end{array}$ & $\begin{array}{l}\text { We were discussing which track to } \\
\text { open our set with, given the style of } \\
\text { the DJ who would be playing before } \\
\text { us. We wanted to find an opening } \\
\text { track that would work well after the } \\
\text { previous DJ and be significantly } \\
\text { different but also energetic enough } \\
\text { not to clear the dance floor. We } \\
\text { discussed it in terms of energy level, } \\
\text { often using contour metaphors, } \\
\text { which are absolutely central to DJing } \\
\text { (peaks and troughs, building it up, } \\
\text { taking it down). }\end{array}$ \\
\hline
\end{tabular}

When asked to describe links between music and shape, she reiterated her relatively large-scale ideas concerning shape in relation to patterns of mood or energy level over different tracks in a set. She linked these moods and energy levels to 'a metaphorical scale of high and low arousal and accompanying notions of contour', which in turn were seen as related to various musical features including tempo, timbre, instrumentation, thickness of texture, and harmonic features. She commented that 'shape is a general concept that is inseparable from all these things'. The ways in which she described building sets is similar to the guidance provided by Broughton and Brewster (2002), in their book How to DJ Properly, for encouraging and controlling the energy on the dance floor (see Figure 1). The authors argue that a DJ's choice of what records to play, and in what order, is central to shaping a set, and that mood and tempo are integral to this. The specific 'arch' shape mix she refers to ('a mix that gets more and more peaky towards the middle and then tapers off towards the end') has been previously noted by Spring (2004) who argued that a 'typical' set "begins softly and builds to an intense peak and then mellows out to bring the dancers down and signal the set's end" (p. 50). 
Up, up and away

This is the norm today, largely because every DJ wants their little two-hour set to peak the night. Crowds respond to it, but only because they're rarely offered anything different. Start off fairly quickly and continue in an upward curve until the dancefloor is banging away so fast that everyone's running on the spot. Not for the faint of heart.

\section{The rollercoaster}

Good pop DJs programme sets that are almost Pavlovian in their effectiveness, and you'll see this style in most carpet-and-chrome nightspots (it lets the DJ run through all the genres and it's good for alcohol sales). Take the tempo gradually up until you reach a frenetic peak, and then drop down dramatically to reggae pace. Repeat. Then repeat again.

\section{The work-out}

This is how most long-set DJs play - they treat the evening as an aerobics lesson. Start out slow with warm-up exercises to let the dancers acclimatise. Gradually shift it up a few gears until you reach a peak, and then hold it there (allowing a few breathers along the way). Finally, gently drop the tempo at the end of the evening to allow for cool-out stretching exercises.

\section{Riding the waves}

David Mancuso started the world DJing with his Loft parties in Manhattan. Pleasingly, he is still doing them over 30 years later. David eases people into his evenings with slower tunes - ambient, jazz, world music - before gradually upping the tempo and making the music more dancefloor friendly. As the evening progresses, he's not afraid to occasionally slow things down, creating a gently undulating night.
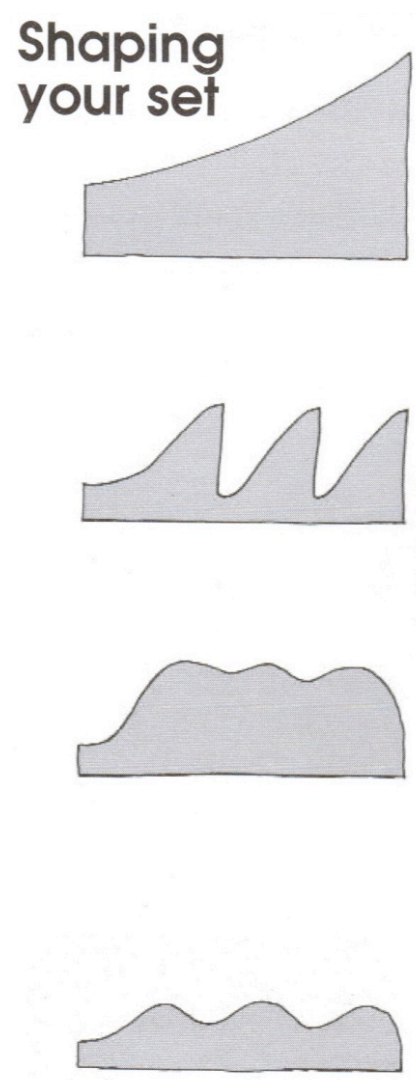

Fig. 1. Guidance on how to 'shape' a DJ set (Broughton \& Brewster, 2002, p. 133)[4]

In addition, she related shape to space, discussing both the acoustics of a particular room and the appropriateness of a track for that space, and her manipulation of the equalisation (EQ) of tracks to make them blend, which as she commented, 'means thinking in terms of frequency space, often on an up/down or left/right scale'. With the exception of the specific technical discussion of equalisation, these comments were similar to those made by classical musicians in the interview studies, who discussed tempo, timbre, thickness of texture and harmonic features as influencing the musical shape. Harpsichordists in particular also discussed listening to the tone of the instrument they were playing and its effect in the particular acoustic of the room in which they were performing.

While the responses of this single participant of the questionnaire study are interesting and insightful, she represents just one view of the importance of shape in relation to music. In addition, her exposure to musicology and classical practices through her degree courses and performance on the violin and piano may also have influenced her ideas concerning music and shape, even when she relates her views in relation to her practice as a DJ. For these reasons, an interview study of the ways in which DJs use the idea of shape or shaping in relation to music was undertaken. It was hoped that a more in-depth study might allow insight into DJs' practices and a comparison with the findings concerning classical musicians outlined above.

\section{METHOD}

The interview study discussed above (Prior, 2012b) provided a clear template for the method of the current study, which was adapted to suit the particular demands of interviewing DJs. The lead author undertook the interviews, as she had knowledge and expertise of DJ practice gained through twelve years of performing experience and four years of teaching DJ skills to students at the University of Leeds.[5] 


\section{Participants}

Three participants were recruited through personal contacts of the lead researcher. Each participant varied in their area of expertise, and in the style(s) of music they most enjoyed performing. They also differed in the equipment they were using, ranging from vinyl decks, to vinyl decks coupled with vinyl emulation software, to digital media players with a vinyl simulation platter (see Figures 2-4 below).

Matthew a.k.a. DJ Kanza is a semi-professional DJ who has been mixing for ten years (20032013) and specialises in drum and bass music.[6] Aged 30, he regularly performs in and around the Midlands, UK, and more recently internationally, and hosts three Internet radio shows per week. Although he has recently learnt to perform on CD decks and Traktor he uses vinyl decks in the majority of his live performances.[7] He is self-taught, using the Broughton and Brewster (2002) book and through the experience and guidance of peers. In the interview, he used $2 \times$ Technics 1210 mkII turntables, Pioneer DJM600 mixer, Ortofon Pro S carts and needles, Sennheiser HD25 headphones, and a desktop PC (Windows) with the software programmes Cool Edit Pro 3 for recording mixes and Edcast (an audio encoder) for broadcasting radio shows (see Figure 2).

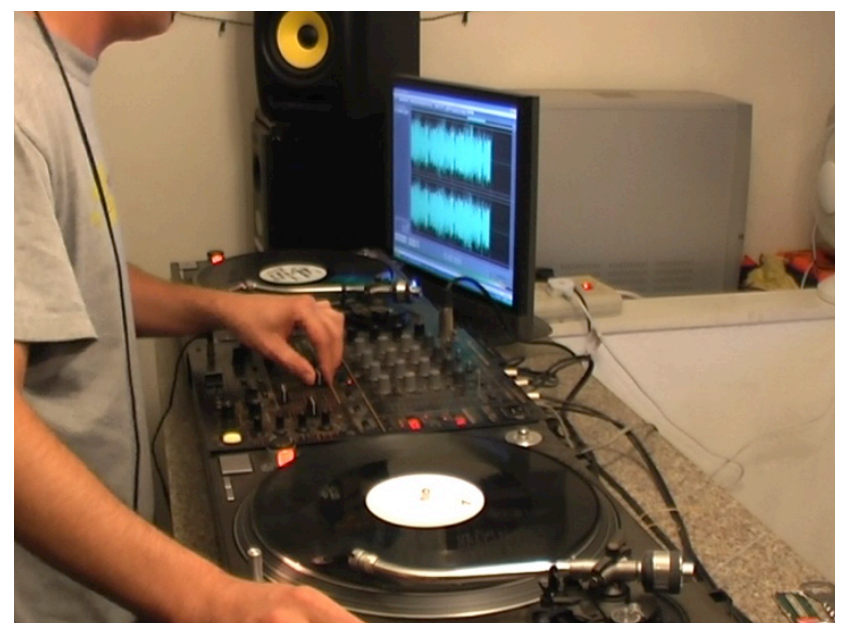

Fig. 2. Matt's equipment

Richard a.k.a. C@ in the H@ [sic] a.k.a. The Doctor is a semi-professional DJ and producer who has been mixing for 15 years (1998-2013) and producing for six (2007-2013).[8] Aged 32, and also selftaught, Rich performs electro swing and glitch hop under the alias C@ in the H@, and hip hop, reggae, bass music, and party mash-up genres under the alias The Doctor, and performs across the UK and internationally. He began his DJing career using only vinyl, but now uses the vinyl emulation software Serato which allows the user to perform with digital music whilst retaining the original feel of vinyl for scratching techniques.[9] He is a member of the Alternative Dubstep Orchestra, a live dubstep orchestra; the Brotherhood of Filth, a three-piece scratch crew; and The Silverbacks, a live hip-hop and funk band consisting of trumpet, drums, guitar, bass, keyboard, synth, scratch DJ and live MCs. He also runs an electro swing-based record label, Ragtime Records, launched in November 2012.[8] In the interview, he used 2 x Technics 1210 mkII, Vestax PMC 05 Pro 3, Ortofon Scratch carts and needles, Sennheiser HD220 headphones, and a Mac Book Pro, Mac OS X Version 10.6.8, with Serato SL-3 hardware and Scratch Live software Version 2.4.2 (see Figure 3). Note the turntables are in 'battle' position to facilitate scratching techniques (cf. Hansen, 2010). 


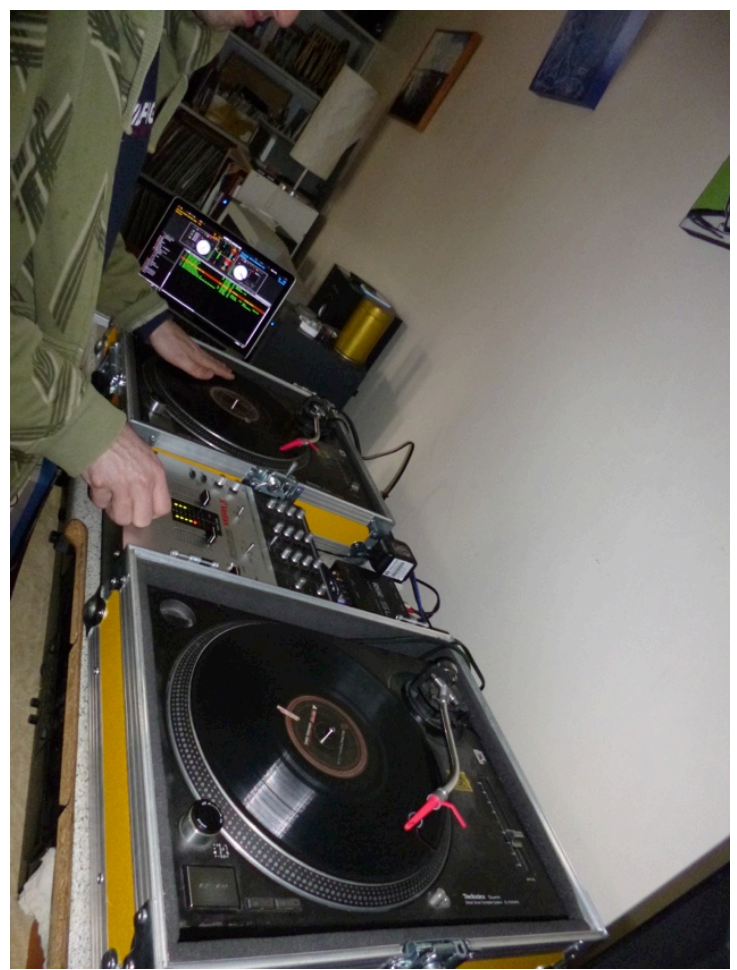

Fig. 3. Rich's equipment

Anthony a.k.a DJ Switch is a professional DJ specialising in turntablism.[10] Aged 23, he started mixing at the age of 11, and was self-taught until completing a course at the DJ Academy at the age of 15 . Starting out with styles such as hip-hop infused rock (he mentions the collaboration between Linkin Park and The Executioners called It's Goin' Down as having been particularly inspiring) and UK garage, he has learnt mixing, scratching and turntablism techniques and has gone on to become one of the most highly regarded multi-genre DJs of his time. He has won the World DMC Championship three times (2008-2010) and has regular guest appearances on national radio stations such as 1Xtra, Radio 1 and the BBC Asian Network. In 2010, he performed closing sets at Glastonbury and Bestival, and in 2011 was the first DJ ever to play at the BBC Proms performing Gabriel Prokofiev's Concerto for Turntables. He is currently involved in a range of projects including the Nottingham-based band Hey Zeus, a four-piece band consisting of DJ, keyboard player, drummer and rapper; Boom Operators which is a six-piece live hip-hop, electronica and dub act featuring beats, bass guitar, beatbox/vox, turntablism and scratching, percussion and electric guitar; Brotherhood of Filth which is dubstep scratch;[8] and Tony is currently one of the forefront DJs of the electro swing genre. He is resident tutor at the DJ Academy, where he teaches turntablism and digital technology courses and also one-to-one tuition in beat juggling.[11] Tony stated that it had taken him approximately ten years of practising (at every available opportunity) in order to reach the standard he was currently performing at, which echoes the findings of previous research by Ericsson, Krampe, and TeschRömer (1993) on the role of practice in acquiring expert performance. 


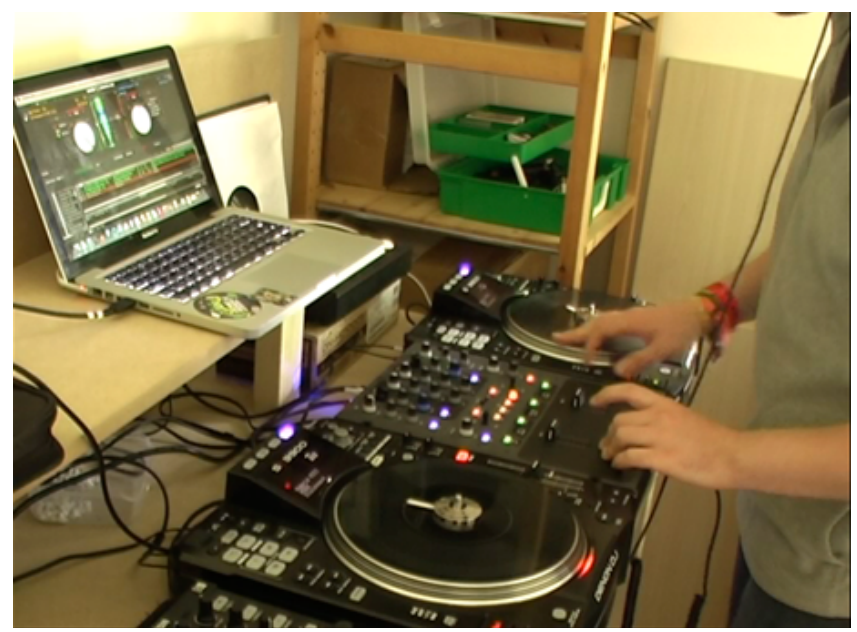

Fig. 4. Tony's equipment

In the interview, Tony used 2 x Denon SC3900 Digital Media Players, a Rane 61 digital mixer, Denon DN-HP1000 headphones and a 13 inch MacBook Pro, Mac OS X Version 10.7.5, with Serato version 2.4.3 (see Figure 4). Given his DMC titles, Tony has been asked by Denon to promote their new equipment and the set-up presented here is at the forefront of digital media players.[10] The Denon SC3900 player is a CD turntable with a nine inch platter that moves in real time and is also a digital controller for most DJ software.

\section{Procedure}

The interview comprised a mixture of musical demonstrations and discussion, focused around unfamiliar records provided by the researcher as well as pieces from the DJs' own collections. Identification of the unfamiliar tracks was a joint effort between the participant and researcher. The interview began with the researcher asking the participant to demonstrate the way in which they would perform with unfamiliar records for approximately five minutes, which was followed by a discussion of the process. Five minutes was chosen because it is approximately the time that would be taken to mix two or three drum and bass records together. The researcher then asked the participant to perform with the records once more, but with a particular focus on the musical shape, or the way in which they were shaping the music. Again, this was followed by a discussion of the process. The participant was then asked to perform the records in the same order without any shaping, and this was also discussed. A more general discussion of their general practice in relation to musical shaping followed, with the participants using familiar examples from their own collections.

The interviews were recorded using an Olympus WS-321M voice recorder and a Panasonic NVGS230 video recorder. The procedure was approved by the ethics committees of King's College London (REP-H/09/10-6) and the University of Leeds (LTMUSC-014).

\section{Method of analysis}

The interviews were analysed using Interpretative Phenomenological Analysis (IPA). Influenced by phenomenology and hermeneutics, this approach is particularly suited to small sample sizes as it focuses on an idiographic understanding of the data in question (Smith, Flowers \& Larkin, 2009). The analysis followed the procedure described by the method's pioneers (Smith \& Osborn, 2003; Smith, Flowers, \& Larkin, 2009), beginning with verbatim transcription of an individual participant's data and subsequent familiarisation with its content before an initial summary was written. Following this, two distinct stages of coding were undertaken: the phenomenological coding focused specifically on understanding the participant's conception of the music they were performing and the ideas they expressed verbally; the interpretative coding allowed patterns to be identified in the data and links to be made with other ideas and the lead researcher's own knowledge. Following this, themes were identified in the data and clustered together before the coding process was reviewed by the second researcher. Each interview was analysed 
individually up to this point, at which time the themes from each interview were compared and an integrative analysis of all the interviews was performed. Finally, a narrative was constructed to describe the findings.

The analysis of the transcribed verbal material was aided by the use of the audio and video recordings during each stage of the analysis. Where participants referred specifically to musical shapes they tried to create - and demonstrated these shapes using gestures or other visual means - video clips were isolated and examined closely in relation to the surrounding interview content. This approach was influenced by the methods demonstrated in Cienki and Müller (2008).

A draft copy of the final paper was provided for participants for reflection and feedback. Matt and Tony felt that their interviews and practices were accurately represented; Rich made a few minor changes and additions, which will be indicated in the results.

\section{RESULTS}

We will first consider the individual perspectives of the DJs, and then bring out similarities and differences in perceptions of musical shaping across the interviews.

\section{Matt}

Matt's extensive vinyl collection (over 3,000 drum and bass records) meant that choosing unfamiliar tracks for him to perform with took some consideration. He was asked to perform with these tracks for five minutes as he would if he were starting a live DJ performance.[12]

After his first performance he talked about the mechanics of mixing. He reported that the most essential skill was listening through headphones to ensure that both tracks are in time with each other by adjusting the pitch fader on the vinyl decks. Maintaining consistency in volume and equalisation were his next concerns ("as you move from one tune to the next, you reduce elements of the out-going tune, increase elements of the in-coming tune, so you get a smooth transition"). He emphasised the role of familiarity in enabling a smooth mixing style ("normally when you're playing with records you know, that information is already in your head from previous use...but you're never entirely sure with a new record what the pitch is and what the volume adjustment is going to be"). He described the transition period as a creative practice, using EQs as improvisational tools; he was 'creating his own tune' from the existing tunes by altering the low, mid and high range elements. He also described the use of special effects (e.g., echo, flange, filters) on the mixer which allowed the emphasis of specific preferred elements (e.g., vocal melody, drum rhythm). He argued these added "a little something extra to the tunes" but maintained that they were easy to over-use ("I'd rather under-use them than over-use them"). He re-emphasised the role of familiarity, and the importance of listening and responding quickly ("particularly when you are mixing two unfamiliar tunes together, it's being aware that things can change at a moment's notice, and being able to react, ear to eye to hand coordination to work out what's starting to sound wrong"). He argued that it is more difficult to be creative with unfamiliar tracks because of the need for a higher level of concentration on the structural features than is required with familiar tracks.

When asked to perform a second time thinking about the shape of music, or musical shaping, his initial response was "I'm not entirely sure music has a shape" but began his performance anyway. When asked to describe his approach, he reported that he visualised each track as a graph ("in my mind's eye I visualise each individual track as a graph with time along the $\mathrm{X}$ axis obviously, and I suppose sound intensity as the Y axis") suggesting that the shape of music is represented by its waveform. Despite his initial comment, he went on to describe his 'tried and tested' mixing style with respect to shape, describing the mix on a large scale (over the course of an hour) and small scale (during the transition between records).

On a large scale, his main aim was to mix records in quick succession using a smooth (rather than 'choppy') mixing style, building the overall sound intensity/energy (he used these terms interchangeably) gradually over the course of an hour whilst allowing for dips in energy at certain points to enable him to build the energy level back up again. We have depicted the shape of the mix he described in a graph which plots sound intensity/energy against time (see Figure 5). This preferred shape represents a combination of the 'Up, up and away' and 'Riding the waves' mixing styles outlined by Broughton and Brewster (2002). The sharp incline in sound intensity during the first five to ten minutes correlates with Matt's use of the opening section of the mix to show off DJ skills and versatility by mixing a diverse selection of tracks 
quickly. He reported he would build the energy for ten minutes, and then after four or five records allow one of the breakdowns (section in a tune where the bass is typically stripped out) to come through to give the audience a break from dancing and to allow him to rebuild the energy. He stressed the importance of variation in tunes over time, and also the role of playing familiar older tunes to please the crowd and add an element of surprise (cf. Huron, 2006).

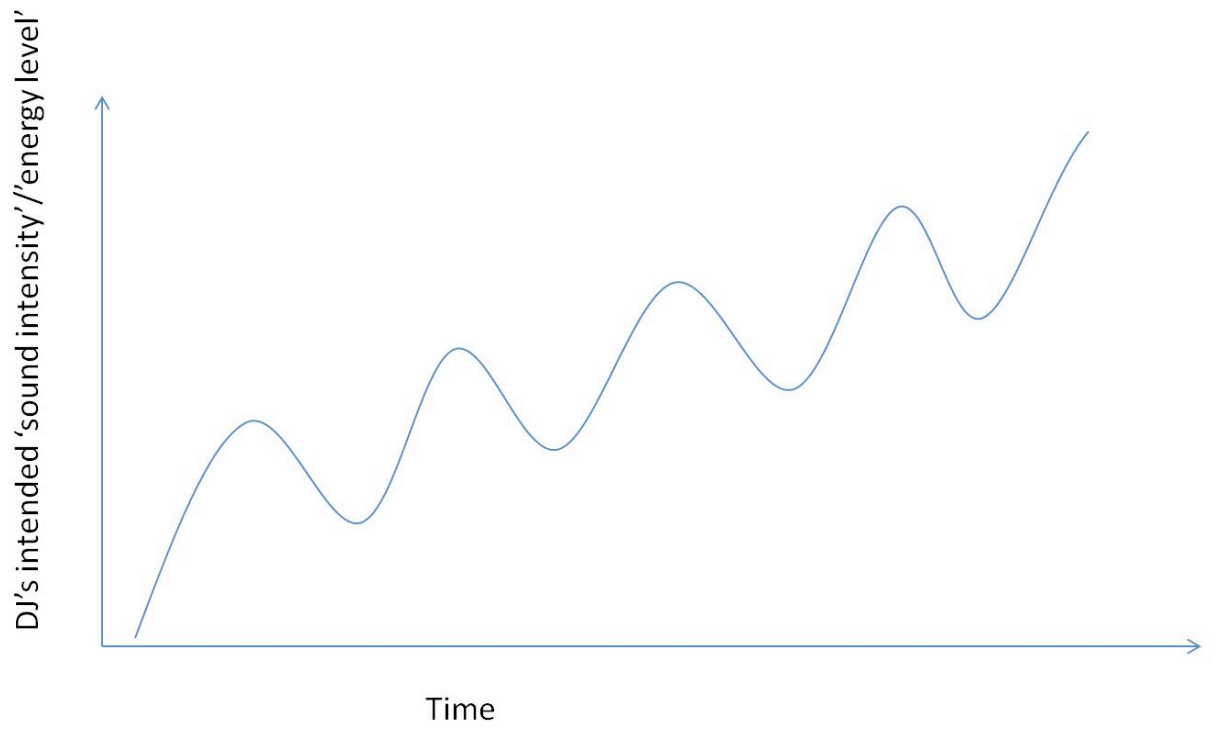

Fig. 5. The shape of Matt's 'tried and tested' mix

On a small scale, Matt's aim was to select tracks which fitted together well ("choosing a tune which complements the existing tune through either similar or opposing elements"). In the transition period between two tracks, he reported that his first step is to identify the track's pattern, which can be done visually by inspecting the grooves on the record. He then focuses on the first entry of the bass line (the 'drop') and on mixing the bass line from the in-coming record before the bass line finishes on the out-going record to maintain consistency in energy level. He then intensifies the mix with creative use of EQs to add extra elements to the tune which "goes beyond what people know from that pre-recorded music". This, he noted, gives the performance a feeling of acceleration without increasing the tempo. Matt also referred to the way in which he used the shape of tracks to vary the intensity, such as bringing the music to a halt unexpectedly ("sometimes for dramatic effect you can use the shape of the record, to have a dramatic pause") or leaving the tune to breakdown so that the overall shape descends into a trough (see Figure 5).

When Matt was asked to perform without any shape or shaping of the music, he described how he had changed his behaviour:

"Basically, I tried to unlearn everything I know about mixing, with the exception of how to beat match cause that would have just sounded horrible. So I did not use the existing shape of the records in any way to complement the shape of the adjacent record; intentionally did not attempt to match the peaks and troughs; intentionally did not use the EQs to add definition to any specific elements of either record. There is existing shape within the music itself so it isn't possible to completely remove shape, but what I set out to do was to not enhance the existing shapes in any way, in the ways that I would normally do when I mix, so basically stripped back all of the elements that I add, or that the DJ would add to a mix by choosing specific points to cue a tune, to drop a tune in, to take the next tune out. I intentionally brought a tune in out of sequence at one point as well, out of phrase, to just make the overall shape more, more muddy, so less defined as a whole so it would be less pleasing and has less direction to the listener"

The discourse of 'unlearning everything' suggests that Matt sees shape as integral to his DJ performances. When asked whether he found it a strange thing to be asked, he argued that he had not really 
thought about it until the interview, and that is was an abstract concept to try to articulate into words due to its subjective nature:

"Well it's not a discussion I've ever had before, the shape of music is something that only really existed in my head, up until this point, although I'm sure that everybody defines the shape of music in some way to themselves but because these things are so very subjective, it wouldn't be necessarily something that you would, discuss with someone else, or you couldn't really draw the shape of music beyond, to me, what I've just explained about it being a graph of intensity against time. There are other people that maybe would say, this music is a triangle, this music is circular, this music is a zig-zag, and if you had synaethesia, obviously music has a lot of other shape, texture and colour elements to it, so, music anyway is quite a difficult thing to put into words, particularly non-vocal music, because it's about the emotions that it stirs up within you so discussing the shape of music is quite an abstract concept, different people would use different language to discuss that"

When asked about words with a similar meaning to shape in a musical context, he suggested 'vibe' or the 'feeling of the music'.

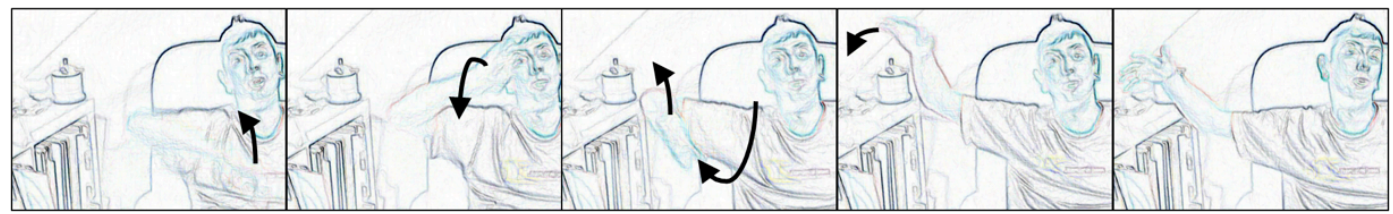

Fig. 6. Matt gestures the shape of an undulating mix (sine wave) (See also Video 1)

Matt stated that he would be more likely to talk about the overall shape of the music if he was performing with another DJ. He said that this would normally take the form of a discussion at a broad level about the selection of tracks they were going to perform, and that a mix with a co-performer tended to be more undulating overall (see Figure 6) because no one individual had complete control. He drew on a recent example of performing with someone for the first time, maintaining that they would not need to have such a detailed conversation the following time they performed together: "that pre-existing discussion regarding shape would be implicit for future reference."

\section{Rich}

Rich performed with several drum and bass records from the first author's personal collection which required him to perform with vinyl (and not Serato).[13] He was unfamiliar with all tracks except for one track 'Movin' Fast' from the album EP Stonehead by the artist Enei so did not perform with this track.[14]

When he talked through his approach to the first performance, he emphasised the importance of familiarity with tunes. He chose vinyl from the Enei album for the first two mixes, referring to this as a "safe bet" because he had some awareness of the artist, and because tracks from the same EP often mix well together. He then talked about mixing straight to the 'drop' because he was not familiar with the introductions of the tracks and wanted to avoid mistakes. He stressed the advantage of being able to see the waveform in Serato as you can ascertain more quickly where structural landmarks are (e.g., breakdowns, samples) to facilitate quick mixing and allow time for scratching. The importance of identifying a sample (e.g., vocal snippet) to scratch with as early on as possible was clearly highlighted in his reflection on the performance.

When Rich was asked to perform with the same tracks again, this time thinking about the shape of music or musical shaping, his initial reaction was jovial (he said "oblong", laughing) but then slightly perplexed ("I don't really know what you mean by that, sorry"). When prompted to take his own concept of what 'musical shaping' was (or was not), he said that he did not think he would do anything differently to the first time round. This suggests that his notion of musical shape (whatever this constitutes or represents) is inherent in his DJ performances already. At the end of the second performance, rather than describing the specific techniques he used to shape the performance, he emphasised that he had not been able to mix in the way he wanted to because it was not possible to see where the samples were. Ideally, he noted, he would have identified a sample to scratch with, started the mix with a slow introduction without a beat so he could 
scratch over the top, and then scratched the second tune straight into a drop. He pointed out that the sample he had wanted to scratch with was on the first tune so he was not able to do this on vinyl format (but this would have been possible on DVS as you can load the same track to play on both decks). Describing hypothetically how he would have performed with his usual set-up (Serato) provided insights into what was important for him in shaping a mix, namely, familiarity with records, a real-time graphical representation of musical materials, and identifying samples to scratch with.

After the second performance, Rich was asked to perform without any shape or shaping of the music. His immediate response was "so you're asking me to play badly?" which implied that a good performance needs shaping. When he talked through his approach afterwards, he said he had intentionally disregarded structural features of the music, by bringing a track in out of phase, and not using the EQs. He went on to say that "trying not to shape seems a bit unnatural" suggesting its implicit nature, which was further supported by his response to the question of whether it was an odd thing to be asked "it [shaping] is a bit of a strange thing to be asked but actually it's something you do without really thinking about it".

He then discussed his conceptions of shape in relation to mixes and tracks, explaining how different mixes can take different shapes, indicating through gesture and the use of contour metaphors (e.g., build it up, take it down). He said a mix might be one 'vibe' all the way through, gesturing a horizontal line, that it might be gradually building throughout, gesturing an upwards line, or that it might be fluctuating up and down, gesturing a sine wave (see Figure 7). The use of a wave gesture can be compared with the 'riding the waves' mixing style outlined by Broughton and Brewster (2002). Rich also emphasised the importance of varying musical styles during his mixes. He reported that if he plays a jungle set, he typically starts with a reggae track to warm up the audience, subsequently moves into jungle tracks, and then returns to reggae later on. This shape can be compared to the 'rollercoaster' mixing style outlined by Broughton and Brewster (2002) in which a DJ builds the tempo and then dramatically reduces it at specific points. He argued that a high level of shaping depends on technical ability and requires taking risks, such as performing reggae and electro swing styles together, or performing drum and bass and then introducing soul music unexpectedly ("all of a sudden there's a massive change of energy, but as long as you keep the shape going").

\section{Horizontal mix}

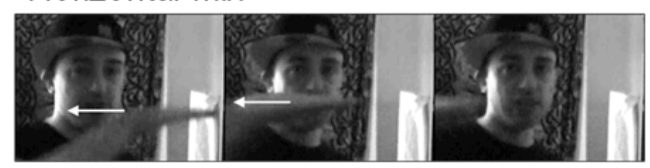

\section{Increasing mix}

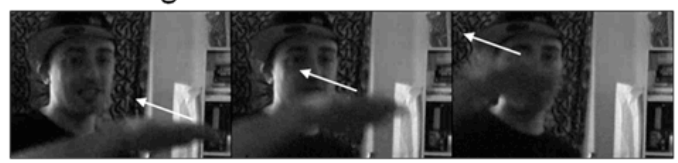

Undulating mix

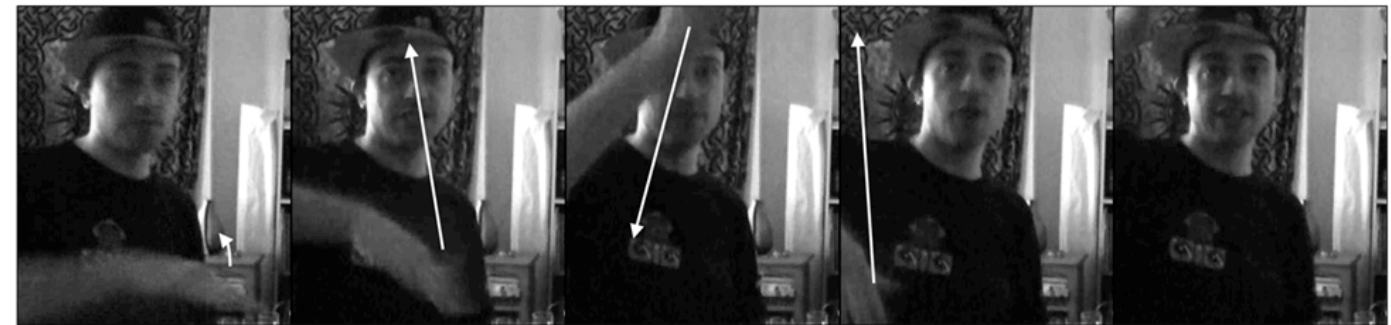

Fig. 7. Rich gestures the shapes of different mixes (See also Video 2)

In addition to mixes, Rich described how the shape of tracks ultimately determined the mixing style that he would employ and drew on two examples to illustrate this (see Figure 8). The first track was The 900 Number by the 45 King. He explained that because the track has "no shape at all", as it is two repeated bars on continuous loop, he has to build the track into a shape by adding a cappella, beat juggling two copies (i.e. of the same track), layering, or equalisation. He also emphasised the need to mix this track quickly (within half a minute) to keep the audience engaged. In contrast, Rich described DJ Shadow's Stem/Long Stem as "extreme shaping" of a track. He described its distinct sections ("starts off really chilled, then Gabba craziness, then chilled again, and then really heavy again") and explained that he would not mix another track or a cappella over the top because the tune has "enough shape of its own". 


\section{Track: 45 King - The 900 Number}

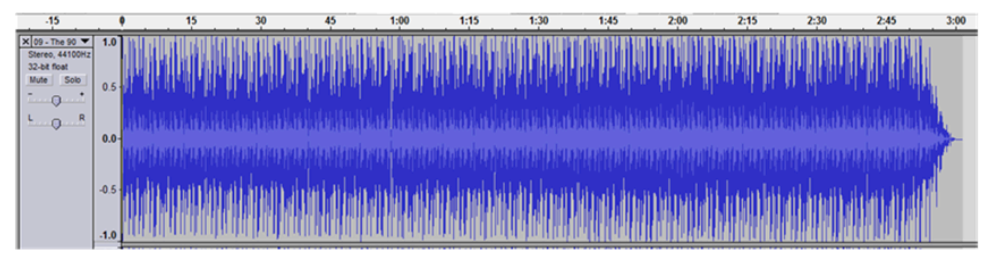

Track: DJ Shadow - Stem/Long Stem

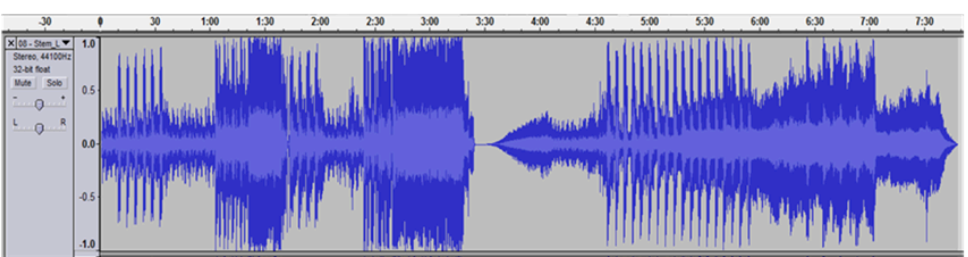

Fig. 8. Rich's examples of tracks with no shape and extreme shaping

Rich also talked about the shape of tracks in relation to his own musical productions. He talked of going through different processes depending on the genre he was producing. For example, when producing electro swing, he identifies samples he wants to use first, then builds a beat, loops the beat and layers the samples. When he is producing dubstep, he builds a beat, then works on the bassline ("to me the bass is the shape") and then adds in additional elements. He emphasised that when producing you have to think about listening and performing ("you need to be able to listen to the track on its own and it needs to be listened to in a DJing capacity, because if DJs can't mix it, then they're not going to play it, unless they're skilled").[15] He illustrated further by describing a current track he was working on, outlining processes he had been through and explaining that it had been necessary to remove some of the elements he had embedded in the track to make it easier to mix. A final point, made in response to the draft paper, was his use of a microphone when performing to emphasise specific 'peak' structural points in his mixes.[16]

Despite initial assertions that he was not sure what was meant by the shape of music, and musical shaping, his accounts suggest that notions of shape are deeply ingrained in his performance practice and music production.

\section{Tony}

Tony was using digital media players so unfamiliar tracks were located in digital form.[17] As with the other DJs, he was asked to perform a five-minute set and then describe his thought processes during the performance.

After the first performance, Tony was able to re-create exactly the mini-mix he had just performed and talk through the decisions he had made. He started by checking that the tunes had roughly similar bpm (beats per minute) in Serato. After this, he selected a track at random, and chose a whooshing noise at the beginning to carry out his first scratching technique. Interestingly, he said "I saw it had a bit of a whooshing noise" rather than "I heard ..." highlighting the central role of the visual waveform in Serato helping him to familiarize himself with the tracks quickly. He started the mix with a scratch technique to "show off his scratching prowess" before turning his attention to identifying cue points. The most fundamental aspect of his mixing was identifying cue points such as key transition points (e.g., bass drop, breakdown) and samples to scratch and "do tricks with", and he emphasized the extent to which this is aided by the colour distribution of the software Serato. He identified one sample (vocal snippet "nasty bass') early on and proceeded to perform a variety of scratch techniques over the top of the first tune using the sample, during which time he was constantly adjusting the EQs, volume, faders and filters to achieve his desired sound. Having found the cue points on the incoming tracks, he then mixed the second tune before the breakdown of the first tune so as to continue the bassline. He argued that it is harder to identify when the tracks are matching each other without definite kicks to latch off, and that once the cue points have been assigned, it allows him to be more flexible and illustrate his technical skills. Other factors he 
mentioned were the importance of listening and responding quickly, familiarity with the tunes ("not having heard these tracks before, just listening out for when the nice time might be to EQ one in and the other out") and the type of mixing style employed (e.g., a 'cutty' mixing style, where he teased bits of previous tune back in, and then teased bits of the next tune in).

Tony was asked to perform again, this time thinking about the shape of music or musical shaping. At the end, he immediately stated that he had preferred things the way he did them in the first performance, and that the request to 'shape' the music had distracted him somewhat. He talked about the difficulty of not knowing the tunes you are performing with, particularly with respect to the pitch matching ("because these are swing drum and bass tracks, some are the parts are not bpm tempo, they were wavering, I was having to push them back in") and the importance of familiarity with the key structural features of the track ("I notice it's not a straight 16 bars, it's 14 and so you have to do something to get around that').

When asked to perform without any shape, or shaping of the music, he asked what was meant by this: "without any shaping, ok (pause), is that, in what kind of sense of not shaping, just mixing tracks together irrespective of anything? Just do weird things?". He was prompted to take his own concept of what 'musical shaping' was (or was not), and he laughed: "ok, this will be interesting, particularly since I am not entirely sure what the question is" and proceeded to start the mix. Afterwards, he described what he had done differently. It became clear that for Tony, 'without shape' was synonymous with 'chaotic'. He took specific elements of the music and played around with them in a different way. He altered the tempo of a track by winding on the vinyl platter manually instead of using the pitch faders in order to create atypical changes, and changed the location of cue points he used, releasing the track at different points in the bar to "see where it ended up" rather than thinking through the most appropriate point at which to bring in the particular element. He stated "if the purpose is to be chaotic, then the act of mixing itself fails really" and went on to note that the most chaotic mix he could have done would have been one without beat-matching.

When asked whether shape was something he usually thought about, or whether it was a strange thing to be asked, he responded:

"I do think about it, because when you asked me to perform for the first time with the tracks I hadn't heard, and then asked me to consider shape, that kind of threw me off, because even though I didn't know them, I could at least see the graphical representation of them, I was already looking at the tracks and thinking, ok, what might be a good place to drop this in to make the mix take a good form"

Note again the use of the visual representation of tracks to facilitate his performance. He broadened the discussion onto the shape of his mixes. As a multi-genre DJ, he reported that different styles of electronic dance music exert a considerable influence on his mixing style:

"if you have a set out, there are a lot of options you have to shape it, so you start by thinking about what kind of genres or what kind of vibe do I want to get, do I want it to be dark or light-hearted, do I want it to change a lot, or do I want it to be quite smooth, and then that informs what kind of genres you'll play or vice versa, whichever genres you want to play in, find the moods within that genre, and from there, that then informs the different techniques you could use or want to use, like, house and trance music is very set in one tempo, very built towards getting the crowd euphoric for that hour, you know, it's all about mood, so the mixing is very straight, it's very gradual and seamless, whereas hip-hop music, hip-hop tracks will be all over the place in genre, it encourages turntablism to be developed, you cut things together because you won't get those big intros to mix, you won't get chance to beat match"

He reported that he would usually do a "rough skeleton structure for the overall shape" which was typically constructed in blocks of tempo, and that the 'red thread' running through his mixes was scratching and turntablism ("because they're the two main things... and they are such a big part of my name and my draw as World Champion"). He argued that turntablism techniques took more consideration of the overall shape ("they require a certain amount of formatting to build up those routines, depending on the source material") than the more 'showy offy effects' such as looping and filters. 


\section{Similarities and differences in DJs' perspectives on musical shape}

There were a number of similarities in these DJs' perspectives on musical shape. Firstly, they emphasised the importance of record selection in shaping the overall contour of a mix (and factors influencing this selection such as the type of night, type of club, the audience, who was performing before and after, and the absence/presence of co-performers). This resonates with responses provided by the female DJ in Prior's (2012c) study which stressed the importance of choosing the 'right' tracks on the basis of mood and energy levels. It also supports assertions that a DJ's selection of what records to play, and in what order, is central to shaping a DJ performance (Broughton \& Brewster, 2002; Montano, 2009; Straw, 1993). Secondly, the DJs argued that there is existing shape inherent within the musical materials, and discussed the ways in which they use the existing shape of tracks to shape the overall mix. Rich's descriptions of how the amount of existing musical shaping within tracks influences his mixing style provide a good illustration of this. This lends strength to accounts provided by the classical musicians in Prior's (2012b) interview study who, when asked to play without shape, emphasised that they could not eliminate shape entirely because of the existing shape within pieces. A third similarity was the key role of familiarity with tunes in shaping a performance, particularly knowledge of the key structural points of a track (e.g., bass drop, breakdown). It was explicitly acknowledged that it is harder to perform with unfamiliar music as it reduces the capacity for improvisation during the transitional period between tracks. Fourthly, all of the DJs, including Prior's questionnaire respondent, reported using controls on the decks and mixer (e.g., faders, equalisation, special effects) to add shape to their DJ performances. Their use of EQs and special effects allows them to foreground specific preferred elements (e.g., vocal melody, drum rhythm) in ways not defined by the music itself. As has been highlighted in previous research (Brewster \& Broughton, 1999, 2012; Moorefield, 2010), DJs go beyond the pre-recorded musical materials they are working with, creating unique compositions, in real-time, in the context of the performance. This was particularly pronounced for Rich and Tony who were using the turntables and mixer as an instrument to manipulate and create sounds in addition to simply mixing records together. A fifth similarity was the visualisation of tracks and mixes as graphs, often expressed through gesture, and in particular as a sine wave of sound intensity/energy over time. It is not clear to what extent their tendency to conceptualise the music in this way is a result of the software they use (e.g., CoolEdit, Serato) which presents each track as a colour distributed waveform. Lastly, the accounts provided by the three DJs underlined the implicit nature of musical shaping; all three seemed initially puzzled about the notion of shape but went on to talk about it fluently in relation to their performances. This is in contrast to the DJ respondent in Prior's study who explicitly linked notions of shape to aspects of her DJ practices from the outset. As discussed previously, this could be due to her exposure to musicology and classical practices through her degree courses.

The main differences in perspectives were related to genre preferences, mixing styles, technical proficiency and the technological equipment used. Matt - who specializes exclusively in drum and bass and is not a turntablist - emphasized a seamless mixing style, and much of the discussion of shape focused on equalization and the transitional period between tracks. Rich and Tony were both multi-genre DJs and turntablists who focused on identifying samples to scratch with and mainly adopted a 'choppy' mixing style. Identifying appropriate samples is fundamental to scratching techniques (see Hansen, 2010) so it is not surprising that they focused intently on this. Recent research has discussed the role of technological developments in changing DJ practices (Farrugia \& Swiss, 2005; Hansen, 2010; Montano, 2010) and the current findings provide supplementary evidence for these debates. Rich and Tony use the digital software Serato which provides a visual representation of the tracks in real-time; both lauded the colour distribution of the software for identifying cue points quickly (the colours of the waveform represent frequencies [e.g., bass is red], the size of waveform represents volume, and the transparency of the waveform indicates whether the sound is transmitted from one or two channels). Serato allows the assignment of cues at key structural points and embeds these cues in the track so that when it is loaded again they are available immediately for use (i.e. they can be jumped to at any point during the mix). Serato also has a range of built-in effects that are not found on traditional mixers. What this means in terms of shaping performances is that DJs have an unprecedented level of control over the sections of the tracks they use, and the length of time and various ways in which they use these during a performance (e.g., looping, scratching samples). Tony reported that many of his routines would not be possible without the software. 


\section{DISCUSSION}

Overall, the findings of this study highlight that shape is an integral part of DJ performances. For the DJs in this sample, shape appeared to be related to musical structure, phrasing, dynamics, and samples; and more broadly to tracks, mixes, mixing styles and turntablism. They use the notion of shape when planning and executing their sets, and consider that performing sets without any shaping involves playing the music badly. There was evidence to suggest a multi-modal understanding of musical shaping: they indicated shape-related ideas using gestures and also referred to the visual representation of the tracks and mixes as an indicator of shaping, as well as controlling musical shape through listening and responding to sound.

If we compare these findings to previous studies with professional classical musicians (Daynes, 2010; Prior, 2012c, 2012b), a number of similarities and differences can be identified. At a broad level, a key similarity is the multi-faceted and flexible nature of shape. In Prior's research, classical musicians used the term in relation to musical structure, expression, emotion and tension, and specific musical features such as phrasing, the melodic line and dynamics. Similarly, DJs in the current study applied shape to multiple musical levels and components. Both groups also expressed shape multi-modally in the form of visual diagrams, graphs or gestures. Prior's classical musicians used arch-shape gestures to indicate phrases, and larger arch shapes and wave patterns to indicate the overall shape of the piece (see Prior, 2012b). DJs in the current research used wave gestures (e.g., sine wave) to represent the overall shape of different mixes. Some of the classical musicians discussed imagining visual ideas of the music they were playing. Several violinists discussed visualising particular types of motion that might fit with a desired sound, such as the idea of spinning thread. Other participants thought about the motion of dancing to achieve the appropriate shaping for a piece. One violinist reported having synaesthesia [18] and described the ways in which she experienced colours in response to particular harmonic features. For her, the harmony, colour and mood were inextricably linked, and this aided her interpretation of the music, thereby influencing her musical shaping. A key finding was the extent to which the DJs reported using the graphical representation of tracks to shape their performances. Being able to see the waveform of the track (rather than inspecting the vinyl to see where changes in the grooves are) allows quicker identification of key structural points and the colour distribution of the waveform provides key information about musical texture. In Prior's research some musicians viewed the musical score as a 'trigger' for shape, that is, as a starting point for ideas about shaping their performance (Prior, 2011, 2012b). These DJs appeared to be using waveforms as starting points for making decisions about musical shaping.

Another key similarity is the way in which both groups of musicians described the use of specific technical approaches and techniques to create and maintain musical shape. These technicalities appeared to be somewhat instrument-specific, as harpsichordists often focused on harmony, violinists on melodic contour, and the DJs on rhythm and texture. To illustrate, many of the violinists in Prior's (2012b) study identified the melodic contour from the score and reported that they would 'follow' or 'mirror' this contour with their musical shaping. Several participants described the general principle of increasing the dynamic level with increasing pitch height and decreasing the dynamic level with descending pitch. Other variations were tied into this idea, including technicalities of fingering or hand position, as well as expressive variations in timing and vibrato. The primary concern of the DJs was beat synchrony-the most fundamental skill of DJ mixing - without which, they asserted, there is no shape. They then discussed ways in which they used the instrument to control the musical texture. This included use of equalisation to foreground or background specific musical elements (adjusting the low, mid and high range frequencies of the sound output); special effects (such as voltage-controlled filters which partition the harmonics out of the waveform); scratching techniques (such as tear, crab, scribble and hydroplane scratches) and turntablism techniques (e.g., beat juggling).

Whilst the classical musicians in Prior's $(2011,2012 b)$ study were able to provide technical descriptions of shaping, there was evidence that they employed heuristics ("short-cuts based on experience that solve problems too complex to resolve quickly enough using analytical thought" Leech-Wilkinson \& Prior, forthcoming) to represent a complex combination of technical devices that create a particular musical shape or sound (see Prior, 2011; Leech-Wilkinson \& Prior, forthcoming). For example, musicians commonly use ideas concerning emotions they wish to communicate through their performance. The musical shaping they wish to use in their performance entails a complex combination of alterations to pitch, duration and timbre which require myriad technical modifications to various specific hand movements. Although they were able to describe their intended modifications to the sound - and the technicalities they employed such as hand positioning, bow pressure, vibrato, or variations in articulation or timing - they 
were more likely to use emotional ideas that encompassed a particular combination of expressive variations used. Another commonly used idea is that of a style of performance: for example, performing a particular piece in a 'historically informed' style denotes a raft of technical ideas concerning musical features from pitch and temperament to ornamentation and phrasing. Less formal ideas may act as heuristics too: participants discussed 'natural' phrasing or shaping, which was used in conjunction with ideas of singing and breathing, suggesting an embodied understanding of the music they were playing. The current research shows that DJs also use metaphorical ideas heuristically to help shape their performances. They were able to describe complex combinations of techniques used to create particular musical shapes or sounds (e.g., selecting the 'right' records, adjusting the faders, controlling equalization, scratching and turntablism techniques) yet they used words such as 'smooth' and 'choppy' to describe their technical approach to mixing, and words such as 'vibe', 'energy level', 'mood', and 'feeling' to signify a particular combination of expressive variations employed. In a similar vein to Prior's musicians then, who expressed "complex and sophisticated 'packages' of musical ideas in a relatively non-specific way" (Leech-Wilkinson \& Prior, forthcoming), DJs were using heuristics as short-cuts. The DJs also used style as a heuristic to guide their musical shaping; for example, house music was associated with the 'smooth' mixing style characterised by gradual shifts in the cross- and up-faders and subtle equalisation, whereas hip-hop was associated with a 'choppy' mixing style characterised by rapid movement of the cross- and up-faders and scratching.

One metaphor that was prevalent in both groups of musicians was the notion of shape as direction, which appeared to package together expressive devices such as variation in the perceived emphasis on notes through tempo and dynamic variations. All five violinists in Prior's study $(2011,2012 \mathrm{~b})$ used movement metaphors to describe music (for example, one participant referred to 'the direction of the notes' to describe the melodic contour). The DJs also used direction metaphors such as 'ascend to a point', 'build up gradually' and 'descend into a trough' to describe the contour of a mix, and phrases such as 'where you go at each point' and 'if you start with very high energy, there's not really anywhere to go' when discussing how they select their records. Anecdotal evidence suggests that DJs like to take the listener 'on a journey' throughout a mix, and the current data provide support for this.

Thus far we have described similarities in the two groups of musicians' perspectives on musical shaping. However, differences in the musical practices of classical musicians and DJs affect musical shaping. For example, DJs' notions of shaping involve selecting repertoire during as well as before a performance, and their selections are made in direct response to audience feedback. In classical performances, audience feedback only occurs at the interval or end of the performance and the repertoire is pre-planned. Another difference was their reliance on technology, and the extent to which technological advancements were reported to facilitate musical shaping. Software programmes like Serato have fundamentally changed DJ practices and, given that technology is constantly evolving, there is likely to be a greater array of digital 'tools' at their disposal which they can use to enhance and create music.

This study explored the perspectives of three male DJs; whilst it is reassuring that many of the aspects of DJ practice discussed were also mentioned by the female participant in Prior's questionnaire study, more studies are needed to ascertain whether the practices of these three musicians are used by other DJs. In Prior's research, recordings of the classical musicians' performances were subject to further analysis using Sonic Visualiser, which provided additional insights into musical shaping. In the current study, DJs were video recorded and they were asked to record the performances through their computers (as they typically would when recording a mixtape); this data should be analysed further to compare 'shaped' and 'nonshaped' versions of the performances. It would also be interesting to record DJs making an hour mixtape. Hansen (2010) argues that mixtapes are "an important medium for DJs to showcase their scratching and mixing skills in more or less official releases" (p. 39). Decisions about what to include and the style to perform in are likely to provide further insights. Finally, future research should broaden the range of musicians, musical genres and instruments explored.

\section{Concluding remarks}

DJ practice is underrepresented in musicological enquiry. This may be because musicology has only started studying popular music relatively recently; because of the lack of formal training courses (rendering the art of mixing a somewhat hidden practice); because of the improvisatory nature of the art, or a combination of these factors; whichever of these, it is clear that more research needs to be carried out. The current study provides a springboard not only for further studies on musical shaping, but for further investigation of the 
many facets of DJ performance. IPA is an appropriate method for this kind of exploratory in-depth study of expert musicians' experiences because it is designed for idiographic investigations. The procedure and analytical technique developed by Prior (2012b) and employed in this research could be used as a template for future investigations.

\section{NOTES}

[1] All correspondence can be addressed to A.E.Greasley@leeds.ac.uk

[2] This research was partly supported by AHRC funding (GRANT No RC/AH/D502527/1) as part of the Centre for Musical Performance as Creative Practice http://www.cmpcp.ac.uk/

[3] Whilst increased demand for formal DJ instruction has led to the establishment of institutions such as the DJ Academy (www.djacademy.org.uk) which began work in 2001 to provide specialist courses and one-to-one tuition, such courses remain rare. There is only one text-book that DJs mention consistently when they are asked how they learned to mix, namely, How to DJ Properly: the Art and Science of Playing Records by Broughton and Brewster (2002). This popular book is based on industry knowledge, drawing insight from professional DJs across the world on a comprehensive range of topics including how to mix, basic scratching techniques, and how to perform live to a crowd. More recent guides on mixing and the DJ industry have emerged (Steventon, 2010; Vorobyev, Coomes, \& Murphy, 2012; Webber, 2007) however the pioneering work of Broughton and Brewster (Brewster \& Broughton, 1999; 2012; Broughton \& Brewster, 2002) is held in high regard among music industry professionals.

[4] From How to DJ: The Art and Science of Playing Records (Properly) by Bill Brewster and Frank Broughton, published by Bantam Press. Reprinted by permission of The Random House Group Limited, and How to DJ Right Y2002, 2003 by Bill Brewster and Frank Broughton, and reprinted with the permission of the publisher, Grove/Atlantic, Inc.

[5] Alinka Greasley a.k.a. DJ Linkz www.soundcloud.com/djlinkz

[6] Matthew Loines a.k.a. DJ Kanza www.soundcloud.com/kanza

[7] Traktor is a DVS (Digital Vinyl System) which allows mixing of digital audio files through manipulating a piece of vinyl, CD, or midi controller. The vinyl is time encoded, which allows mapping of an audio file onto the disc/platter, and the software offers a range of features including automatic synchronization of tracks, looping, effects, real-time track management. The development of this technological interface made it possible for DJs to continue mixing by manipulating vinyl (or CDs) whilst allowing the benefits associated with digital mixing.

[8] Richard Shawcross a.k.a. C@ in the H@www.facebook.com/Cat.In.The.Hat.Swing

Richard Shawcross a.k.a. The Doctor www.facebook.com/TheDoctor.UKBass

Alternative Dubstep Orchestra www.facebook.com/AlternativeDubstepOrchestra

Brotherhood of Filth www.facebook.com/brotherhood.of.filth

Brotherhood of Filth demo www.youtube.com/watch? $\mathrm{v}=$ FmlnIg4Qcok

The Silverbacks www.facebook.com/TheSilverbacks

Ragtime Records www.facebook.com/RagtimeRecords

[9] Serato Scratch Live is a DVS (Digital Vinyl System) which allows mixing of digital audio files using the turntables as an interface, thus preserving the hands-on control and feel (e.g., appearance, weight, texture) of DJing with vinyl.

[10] Anthony Culverwell a.k.a. DJ Switch www.djswitchbeatz.co.uk

Check out his DJ skills here:

Part 1: www.youtube.com/watch? $\mathrm{v}=1 \mathrm{BNtxLKU1KA}$

Part 2: www.youtube.com/watch?v=OkL9xK3 jag

Part 3: www.youtube.com/watch? $v=w z F Z N$ tluH0 $\&$ feature $=$ endscreen $\& N R=1$ 
DMC World Championships www.dmcdjchamps.com/

2008 DMC routine: $w w w . y o u t u b e . c o m / w a t c h ? v=F r i w J c 3 q 8 s w \&$ feature=player_embedded\#

2009 DMC routine: www.youtube.com/watch? $\mathrm{v}=\mathrm{Qclq} \mathrm{T} 1 \mathrm{BhjQ}$

2010 DMC routine: www.youtube.com/watch?v=NF FbtT-25A

Concerto for Turntables and Orchestra by Gabriel Prokofiev

DJ Switch and the NYO, BBC Proms

Part 1: http://tinyurl.com/switchproms2011part1

Part 2: http://tinyurl.com/switchproms2011 part2

Denon demo of SC3900 http://www.youtube.com/watch?v=X5AvgtJftW4

Hey Zeus www.myspace.com/heyzeussound

Boom Operators https://soundcloud.com/boomoperators

[11] Beat-juggling is the act of manipulating two or more samples/tracks via manual looping and switching between the records to make a new rhythm, pattern, melody or vocal phrase. A simple beat juggle may take the form of two copies of the same track and looping a two-bar phrase, which is achieved by manually rewinding one record to the beginning of the phrase whilst the second record is playing the phrase, and then vice versa. The length of the phrase may be of any duration, may be of two or more different phrases, or even of different tracks, depending on the complexity desired by the DJ and/or their technical ability.

[12] Musical materials (Matt)

Track 1: Devise \& Three A (feat. Morgan) - Working Girl

Track 2: Stakka \& Skynet - Clockwork (Skynet remix)

Track 3: Nolige - Hunted

[13] Musical materials (Rich)

Track 1: Enei \& Riya - No Fear

Track 2: Enei, Eastcolors \& Noel - Cracker (Jubei remix)

Track 3: Enei - Stonehead

Track 4: Seba \& Paradox - As If

[14] Enei - Movin' Fast (from Stonehead EP) http://www.criticalmusic.com/artist/enei/

[15] When reflecting on the final draft of the paper, Rich felt there needed to be an illustration of why a DJ might find it hard to mix a track. He used the example of when a producer adds an extra bar to a typical structure: "if there is an extra bar added into the arrangement it will require extra skill to pull off a mix, usually in dance music there are series of 16 bar sections (or 8 or 32 bar sections) but some tunes add an extra bar in between each set of 16, so, as a DJ mixing a standard 16 bar track into another that is $16,1,16$, then they have to think more about what they will do with the mix, and some less experienced DJs will just shy away from mixing the track for fear of making a mistake."

[16] "One thing I also didn't mention in the interview was the use of a microphone. Often when I'm DJing I will use the microphone to hype the crowd before a really heavy drop to remind them that this part of the mix is a peak and they should really go for it. If you were do that on each mix it would lose its effect, but used in the right places it can help to shape the set."

[17] Musical materials (Tony)

Track 1: Phil Mac - Swing that Music

Track 2: Schlachthofbronx (feat. Spoek Mathambo \& Bigspace) - Nasty Bass

Track 3: Scatman Crothers - Keep that Coffee Hot (Defunk remix)

[18] Synaesthesia is a neurological condition in which stimulation of one sensory pathway (e.g., auditory) leads to involuntary experiences in a second sensory pathway (e.g., visual) (Cytowic, 2002; Simner, 2012). Research has shown that sound-colour synaesthetes may associate different key signatures with specific colours (e.g., D Major/blue) (Berman, 1999; Sacks, 2007); lighter colours with higher pitches (Ward, Huckstep, \& Tsakanikos, 2006), and particular instruments or musical genres with specific colours (Mills, Boteler, \& Larcombe, 2003). 


\section{REFERENCES}

Berman, G. (1999). Synaesthesia and the arts. Leonardo, Vol. 32, No. 1, pp. 15-22.

Brewster, B., \& Broughton, F. (1999). Last Night A DJ Saved My Life. London: Headline Publishing.

Brewster, B., \& Broughton, F. (2012). The Record Players: The Story of Dance Music told by History's Greatest DJs. United Kingdom: Virgin Books.

Broughton, F., \& Brewster, B. (2002). How to DJ (Properly): The Art and Science of Playing Records. London: Bantam Press.

Cienki, A., \& Müller, C. (2008). Metaphor and Gesture. Amsterdam: John Benjamins Publishing Company.

Cytowic, R.E. (2002). Synaesthesia: A Union of the Senses (2nd Ed.). Cambridge, MA: MIT Press.

Daynes, H. (2010). Music and Shape. Paper presented at the Shaping Music in Performance Conference: Workshop I, King's College, London. Available from http://www.cmpcp.ac.uk/sw1hd.pdf

Ericsson, K.A., Krampe, R.T., \& Tesch-Römer, C. (1993). The role of deliberate practice in the acquisition of expert performance. Psychological Review, Vol. 100, No, 3, pp. 363-406.

Farrugia, R., \& Swiss, T. (2005). Tracking the DJs: Vinyl records, work and the debate over new technologies. Journal of Popular Music Studies, Vol. 17, No. 1, pp. 30-44.

Ginsborg, J., \& Prior, H.M. (2011). First encounters of the musical kind: Strategies for learning music. Paper presented at the Performance Studies Network International Conference, University of Cambridge. Available from http://www.cmpcp.ac.uk/online\%20resource\%20Saturday/PSN2011_Ginsborg_Prior.pdf

Hansen, K.F. (2002). The basics of scratching. Journal of New Music Research, Vol. 31, pp. 357-365.

Hansen, K.F. (2010). The acoustics and performance of DJ scratching: Analysis and modelling. Doctoral thesis. KTH Royal Institute of Technology. Available from http://www.speech.kth.se/ kjetil/thesis/

Hansen, K.F., \& Bresin, R. (2006). Mapping strategies in DJ scratching. Proceedings of the Conference on New Interfaces for Musical Expression. Paris, France: IRCAM, Centre Pompidou, pp. 188-191.

Huron, D. (2006). Sweet Anticipation: Music and the Psychology of Expectation. Cambridge, MA: MIT Press.

Leech-Wilkinson, D., \& Prior, H.M. (forthcoming). Heuristics for expressive performance. In: D. Fabian, E. Schubert, \& R. Timmers (Eds.), Expressiveness in music performance: Empirical and cultural approaches. Oxford: Oxford University Press.

Mills, C.B., Boteler, E.H., \& Larcombe, G.K. (2003). "Seeing things in my head": A synaesthete's images for music and notes. Perception, Vol. 32, No. 11, pp. 1359-1376.

Montano, E. (2009). DJ culture in the commercial Sydney dance music scene. Dancecult: Journal of Electronic Dance Music Culture, Vol. 1, No. 1, pp. 81-93.

Montano, E. (2010). How do you know he's not playing Pac-Man while he's supposed to be DJing? Technology, formats and the digital future of DJ culture. Popular Music, Vol. 29, No. 3, pp. 397-416. 
Moorefield, V. (2010). Modes of appropriation: covers, remixes and mash-ups in contemporary popular music. In: A. Bayley (Ed.), Recorded Music: Performance, Culture and Technology. Cambridge: Cambridge University Press, pp. 291-306.

Prior, H.M. (2011). Exploring the experience of shaping music in performance. Paper presented at $C M P C P$ Performance Studies Network International Conference. Faculty of Music, University of Cambridge. Available from http://www.cmpcp.ac.uk/online\%20resource\%20Friday/PSN2011_Prior.pdf.

Prior, H.M. (2012a). Methods for exploring interview data in a study of musical shaping. Proceedings of $12^{\text {th }}$ International Conference on Music Perception and Cognition (ICMPC) $/ 8^{\text {th }}$ Triennial Conference of the European Society for the Cognitive Sciences of Music (ESCOM), p. 59. Thessaloniki: ICMPC/ESCOM. Poster available from http://www.cmpcp.ac.uk/Prior_methods.pdf

Prior, H.M. (2012b). Report for Interview Participants. Available from http://www.cmpcp.ac.uk/Report\%20for\%20interview\%20participants.pdf

Prior, H.M. (2012c). Report for Questionnaire Participants. Available from http://www.cmpcp.ac.uk/Prior Report.pdf

Prior, H.M. (forthcoming). Using and creating identities through musical shape: an IPA case study.

Sacks, O. (2007). Musicophilia. London: Picador.

Simner, J. (2012). Defining synaesthesia. British Journal of Psychology, Vol. 103, No. 6, pp. 1-15.

Smith, J.A., Flowers, P., \& Larkin, M. (2009). Interpretative Phenomenological Analysis. London: Sage Publications Ltd.

Smith, J.A., \& Obsorn, M. (2003). Interpretative phenomenological analysis. In: J.A. Smith (Ed.), Qualitative Psychology: A Practical Guide to Research Methods. London: Sage Publications, pp. 51-80.

Spring, K. (2004). Behind the rave: Structure and agency in a rave scene. In: A. Bennett \& R.A. Peterson (Eds.), Music Scenes: Local, Translocal and Virtual. Nashville: Vanderbilt University Press, pp. 3-25.

Straw, W. (1993). The booth, the floor and the wall: dance music and the fear of falling, Public, Vol. 8, pp. 169-182.

Steventon, J. (2010). DJing for Dummies ( $2^{\text {nd }}$ Ed.). Chichester: John Wiley \& Sons.

Vorobyev, Y., Coomes, E., \& Murphy, B. (2012). Beyond Beatmatching: Take Your DJ Career to the Next Level. E-book: Mixed in Key Publications.

Ward, J., Huckstep, B., \& Tsakanikos, E. (2006). Sound-colour synaesthesia: To what extent does it use cross-modal mechanisms common to us all? Cortex, Vol. 42, No. 2, pp. 264-280.

Webber, S. (2007). DJ Skills: The Essential Guide to Mixing and Scratching. Burlington, MA: Focal Press. 